С. Ф. Чалий, В. О. Лещинський, І. О. Лещинська

Харківський національний університет радіоелектроніки, Харків, Україна

\title{
ІНФОРМАЦІЙНА ТЕХНОЛОГІЯ ПОБУДОВИ ПОЯСНЕНЬ 3 УРАХУВАННЯМ ТЕМПОРАЛЬНИХ ЗМІН У ВИМОГАХ КОРИСТУВАЧІВ РЕКОМЕНДАЦЙНОЇ СИСТЕМИ
}

\begin{abstract}
Анотація. Предметом вивчення в статті $є$ процеси формування пояснень для персоналізованих рекомендацій щодо вибору товарів та послуг в рекомендаційних системах. Метою $є$ розробка інформаційної технології побудови деталізованих пояснень щодо запропонованого персонального переліку предметів в рекомендаційній системі з урахуванням темпоральних змін у вимогах споживачів для підвищення ефективності продажів товарів та послуг в системах електронної комерції. Завдання: розробка підходу до побудови темпоральних правил для формування пояснення на основі порівняння кількості продажів на послідовності інтервалів часу; розробка технології побудови темпорально-орієнтованих пояснень щодо рекомендацій з вибору предметів в рекомендаційних системах. Використовуваними підходами є: підходи до побудови пояснень щодо рекомендацій з урахуванням змін уподобань користувачів 3 часом. Отримані наступні результати. Розроблено підхід до побудови темпоральних правил, що визначають темпоральну динаміку вподобань користувачів рекомендаційної системи. 3 використанням темпоральних правил розроблено технологію побудови та деталізації пояснень, що враховують зміни вимог користувачів з часом. Висновки. Наукова новизна отриманих результатів полягає в наступному. Запропоновано інформаційну технологію побудови деталізованих пояснень щодо рекомендацій з урахуванням змін вимог користувачів 3 часом. Технологія використовує моделі темпоральних правил та темпоральну модель інтерфейсу пояснень. Технологія передбачає послідовну побудову базових пояснень з урахуванням темпоральної динаміки вподобань користувачів, подальшу деталізацію пояснень по інтервалам часу на основі узгодження темпоральних знань, а також формування інтерфейсу деталізованих пояснень з відображенням базових змін уподобань користувачів та альтернативних змін на визначених інтервалах часу. У практичному плані технологія орієнтована на підвищення довіри споживача до отриманої рекомендації на основі відображення збільшення попиту на рекомендовані товари. Використання технології забезпечує формування для користувача раціонального підтвердження рекомендації у вигляді комбінації кількісних та якісних показників, що сприяє збільшенню продажів у відповідній системі електронної комерції.
\end{abstract}

Ключові слова: рекомендаційні системи, пояснення, формування рекомендацій, формування пояснень, критерії оцінки пояснень, темпоральні правила.

\section{Вступ}

Рекомендаційні системи надають персональний перелік товарів та послуг, що відповідає інтересам споживача та має підвищити продажі цих предметів. Такі системи зазвичай використовуються у складі систем електронної комерції. Рекомендації формуються з урахуванням схожості характеристик предметів, або ж подібності поведінки споживачів. Подібність поведінки споживачів визначається на основі явного та неявного зворотного зв'язку. Перший представлений рейтингами товарів та послуг, які надає користувач. Він відображає суб'єктивне ставлення користувача до рекомендованих предметів. Неявний зв'язок відображений покупками предметів та об'єктивно характеризує потреби споживача [1].

Сучасні алгоритми формування рекомендацій досить ефективно передбачають вимоги користувача на основі аналізу даних про покупки та рейтинги [2]. Однак така інформація не завжди є доступною для нових користувачів [3], а також може бути спотвореною в результаті шилінг-атак, що призначені для штучного підвищення рейтингів цільових товарів [4].

В результатів рекомендації можуть не враховувати інтереси споживача, що зменшує довіру до рекомендаційної системи.
Тому для підвищення довіри користувача в останні роки рекомендації доповнюються поясненнями $[5,6]$. Пояснення фактично розкриває причини рекомендації предмета конкретному користувачеві. Пояснення формується на основі знань про поведінку споживача або про зв'язок між характеристиками товарів та вибором користувача [7].

Пояснення є контекстно-орієнтованим. Одним iз аспектів контексту $є$ темпоральний аспект. В даному розрізі враховуються зміни вподобань користувачів з часом $[8,9]$. Облік темпоральних змін дає можливість доповнити рекомендації та пояснення $з$ урахуванням актуальних, самих останніх вимог користувача та використати пояснення в онлайн-режимі роботи рекомендаційної системи [10]. Зазначене свідчить про актуальність доповнення рекомендацій поясненнями, що враховують темпоральну динаміку вподобань споживача і, тим самим, мотивують його до покупок рекомендованих товарів та послуг.

Існуючі підходи до побудови пояснень щодо рекомендацій використовують методи формування витлумачень в експертних та прецедентних системах [11]. Знання для побудови пояснень можуть бути отримані автоматизованим способом. Для побудови пояснень на основі автоматизовано сформованих знань запропоновано використовувати регресійну модель [12]. 
Однак темпоральні аспекти в такій моделі не враховуються.

В роботах $[3,13]$ пропонується формувати рекомендації та пояснення до них з урахування темпоральної динаміки вподобань користувачів.

Інтегральне пояснення в роботі [14] формуються 3 використанням темпоральних правил, що були запропоновані в роботі [15].

Деталізацію інтегрального пояснення з урахуванням зміни потреб користувачів з часом представлено в роботі [16].

Таке інтегральне пояснення може бути представлено 3 використанням моделі інтерактивного інтерфейсу з темпоральними параметрами, що була запропонована в роботі [17].

Однак розглянуті підходи, методи та моделі охоплюють лише окремі аспекти формування пояснень щодо рекомендацій з урахуванням темпоральної динаміки потреб користувачів. Задача розробки інформаційної технології побудови темпорально-орієнтованих пояснень, яка б інтегрувала весь процес формування тлумачень в рекомендаційних системах, потребує подальших досліджень

Метою статті $\epsilon$ розробка інформаційної технології побудови деталізованих пояснень щодо запропонованого персонального переліку предметів в рекомендаційній системі з урахуванням темпоральних змін у вимогах споживачів для підвищення ефективності продажів товарів та послуг в системах електронної комерції.

Досягнення поставленої мети передбачає вирішення наступних задач:

- розробка підходу до побудови темпоральних правил для формування пояснення на основі порівняння продажів на послідовності інтервалів часу;

- розробка технології побудови темпоральноорієнтованих пояснень щодо рекомендованого переліку товарів та послуг в рекомендаційній системі.

\section{Підхід до побудови темпоральних правил для пояснень в рекомендаційній системі}

Темпоральні правила [15] орієнтовані на підтримку управлінських рішень і тому задають порядок у часі для пар подій.

Однак при використанні таких правил для побудови пояснень ці правила мають бути адаптовані 3 урахуванням наступних особливостей процесу вибору користувачів:

- узагальнено вибір користувачів відбувається 3 прив'язкою не до конкретного моменту, а до інтервалу часу; наприклад, обчислюється кількість покупок певного предмету за день або за місяць;

- ваги темпоральних правил враховують зміни вподобань користувачів, що досягається обрахуванням змін у кількості проданих товарів та послуг (або зміни їх рейтингів).

Таким чином, темпоральні правила для побудови пояснень встановлюють залежності між парами інтервалів часу. Вага правил, що визначає їх важливість, обчислюється на основі змін у продажах або рейтингах між визначеними інтервалами часу.

Послідовність формування темпоральних правил для побудови пояснень щодо рекомендацій містить у собі такі кроки:

Крок 1. Визначення рівня деталізації часу (година, день, місяць, тощо) для виділення темпоральних інтервалів.

Крок 2. Побудова темпоральних правил типів NeXt та Future [15] для усіх можливих пар попередніх та поточного інтервалу. В якості поточного виступає останній інтервал в рамках визначеного періоду часу.

Крок 3. Обчислення ваг темпоральних правил як різниці у продажах між поточним та усіма попередніми інтервалами 3 подальшою нормалізацією отриманих ваг. Нормалізація дає можливість порівнювати правила для різних періодів часу.

Отримані в результаті застосування даного підходу зважені темпоральні правила дають можливість сформувати кількісну оцінку темпоральної динаміки вподобань користувачів рекомендаційної системи.

\section{Інформаційна технологія побудови темпорально-оріснтованих пояснень}

Розроблена технологія базується на використанні темпоральних правил, що формуються 3 врахуванням специфіки вибору користувача рекомендаційної системи згідно розглянутого в попередньому підрозділі підходу. Технологія передбачає побудову контекстних пояснень 3 використанням розширеного тлумачення контексту. Контекст визначає умови та обмеження вибору користувача рекомендаційної системи [18]. Розширене представлення контексту передбачає, що умови вибору споживача можуть бути визначені як на основі характеристик предметної області (статична складова), так і у темпоральному аспекті (динамічна складова).

Остання складова відображає зміни стану предметної області і, отже, дає можливість визначити актуальні значення параметрів контексту, які впливають на вибір користувача.

Окреме використання динамічної складової дає можливість використати узагальнену оцінку змін у вимогах споживача. Така узагальнена оцінка базується на зміні рейтингів або кількості покупок визначеного товару або послуги з часом. Використання динамічної складової дає можливість оперативно, в онлайн-режимі, відкоригувати рекомендації та пояснення до цих рекомендацій навіть в умовах неповноти інформації про контекст вибору споживача.

В цілому, в рамках розробленої технології, пояснення щодо вибору конкретного товару або послуги формуються на основі даних про попит користувачів на цей предмет.

Зміна попиту є об'єктивним фактором, оскільки споживачі «голосують» своїми грошима. На відміну від кількості продажів, рейтинги товарів або послуг можуть бути спотворені в результатів шилінг-атак [4]. 
В основі розробленої технології лежить ідея про те, що збільшення попиту на рекомендований предмет на поточному інтервалі часу підвищує довіру споживача до отриманої рекомендації. Така ідея широко використовується в рекомендаційних системах: окремі товари маркуються як найбільш популярні серед споживачів. Однак маркування популярності товарів не містить у собі темпоральну складову. Тобто такі товари могли користуватись широким попитом у минулому сезоні, однак у поточний момент часу вони не є актуальними. Тому пояснення, згідно запропонованої технології, має відображати зміни вподобань 3 часом. Збільшення попиту в поточний момент, що підтвердить популярність рекомендованого товару, пояснює причини відбору предмету до переліку рекомендованих. 3 іншого боку, у випадку зменшення поточного попиту, користувач може отримати додаткове пояснення щодо циклічності змін вподобань користувачів. Наприклад, попит зменшився на поточному тижні, оскільки на минулому тижні була проведена рекламна акція, що привела до локального збільшення продажів. Таке пояснення також визначає «чесність» роботи рекомендаційної системи $\mathrm{i}$, відповідно, орієнтовано на збільшення довіри споживача.

Запропонована технологія містить у собі наступні фази:

Фаза 1. Формування інтерактивного інтерфейсу представлення пояснень.

Фаза 2. Формування темпоральних правил, що задають знання щодо змін попиту користувачів 3 часом.

Фаза 3. Побудова пояснення з урахуванням темпоральної динаміки вподобань користувачів.

Фаза 4. Деталізація пояснень 3 урахуванням циклічних та еволюційних змін попиту споживачів.

Фаза 5. Коригування пояснень користувачем 3 урахування динамічної складової контексту.

На першій фазі в рамках інтерактивного інтерфейсу [17] визначаються період та рівень деталізації часу для пояснення. Або ж ці дані формуються за замовчуванням на основі конфігураційних даних.

На другій фазі формуються темпоральні правила згідно розглянутого в попередньому підрозділі підходу.

На третій фазі з використанням методу [14] формується базове пояснення, що враховує темпоральну динаміку вподобань користувачів рекомендаційної системи.

Темпоральна динаміка задається на послідовності інтервалів $\Delta \tau_{j}$ в рамках визначеного періоду часу $T$ :

$$
\begin{aligned}
& T=\left\langle\Delta \tau_{1}, \Delta \tau_{2}, \ldots, \Delta \tau_{j}, \ldots, \Delta \tau_{|T|}:\right. \\
& \left.\left(\forall \tau_{j} \in \Delta \tau_{j}, \forall \tau_{j+1} \in \Delta \tau_{j+1}\right) \tau_{j}<\tau_{j+1}\right\rangle .
\end{aligned}
$$

Такі інтервали визначаються згідно заданого рівня грануляції часу, наприклад, день, тиждень, місяць, тощо.
Зміна вподобань $g_{i, j}$ користувачів щодо $i$ предмету для послідовності попередніх інтервалів у порівнянні з поточним інтервалом $\Delta \tau_{|T|}$ визначається як сума ваг темпоральних правил, що описують можливі темпоральні зв'язки між інтервалами $\Delta \tau_{j} \in T$ та поточним інтервалом $\Delta \tau_{|T|}$ :

$$
g_{i, j}=\sum_{j: \Delta \tau_{j} \in T_{j}} w_{i, j}
$$

де $w_{i, j}$ - нормалізована вага темпорального правила, що пов'язує інтервал $\Delta \tau_{j}$ із інтервалом $\Delta \tau_{|T|}$.

Темпоральна динаміка вподобань користувачів $G_{i}$ щодо $i$ - предмету відображається упорядкованою у часі послідовністю значень $g_{i, j}$ на інтервалах $\Delta \tau_{j}$ :

$$
\begin{aligned}
& G_{i}=\left\langle g_{i, 1}, g_{i, 2}, \ldots, g_{i, j}, \ldots, g_{i,|G|}:\right. \\
& \left.\Delta \tau_{j}=\left[\tau_{j}, \tau_{j+1}\right)\right\rangle .
\end{aligned}
$$

Результатом даної фази є пояснення $E$ у вигляді числового значення змін у попиті на визначений товар за умови, що ці зміни є позитивними, тобто має місце збільшення попиту на поточному інтервалі порівняно 3 попередніми інтервалами в рамках періоду часу:

$$
E=\sum_{j=1}^{|G|} g_{i, j} \mid E>0
$$

На четвертій фазі при побудові пояснення враховується нестійкий попит на цільовий предмет. При циклічних змінах попиту на товар або послугу пояснення $E$ може бути негативним. Для того, щоб воно могло задовільнити споживача, базове пояснення доповнюється альтернативним деталізованим поясненням, яке відображає вплив зовнішніх факторів на вибір користувача. На даній фазі використовується метод деталізації пояснень [16].

Згідно даного методу при деталізації пояснень виконується узгодження знань у темпоральному аспекті. Темпорально узгоджені знання відображають однотипні зміни попиту споживачів. Для узгодження використовується відношення пояснення.

Якщо знання відповідають цьому відношенню, то вони $є$ узгодженими. Тобто якщо пояснення показує збільшення попиту на товар або послугу, то узгодженими будуть темпоральні правила, які теж відображають збільшення попиту.

За результатами узгодження із повної множини темпоральних правил $E$ виділяють підмножину неузгоджених знань $E^{-}$. За допомогою цих знань формується альтернативне пояснення, яке вказує на зміни попиту на предмет для визначених інтервалів часу.

Узгоджені правила $E^{+}$відповідають відношенню пояснення [16]: 


$$
E_{i}^{+}=\left\{g_{i, j}: \forall j g_{i, j} \operatorname{Expl} E\right\}
$$

Оскільки пояснення деталізується лише у випадку зменшення попиту, то відбір неузгоджених правил відбувається за критерієм:

$$
E^{-}=\sum_{j=1}^{|G|} g_{i, j}: g_{i, j}>0 \mid E<0
$$

На основі неузгоджених правил формується деталізоване пояснення для окремих інтервалів 3 $g_{i, j}>0$. Така деталізація показує збільшення попиту на товар у попередні періоди.

На п’ятій фазі використовуються інтерактивні властивості інтерфейсу пояснень [17]. В залежності від представлених значень основного та альтернативного, тобто деталізованого пояснення виконується уточнення темпоральних параметрів. Після уточнення реалізується третя фаза технології. У випадку достатньої деталізації пояснень дана фаза не виконується та реалізація технології завершується.

Розглянута технологія формування пояснень може бути інтегрована із існуючими підходами до побудови пояснень на основі розподілу рейтингів користувачів.

Розподіл рейтингів відображає явні вподобання споживачів без урахування фінансової складової. Тобто схожі рейтинги можуть бути виставлені аналогічним товарам 3 різними властивостями лише тому, що ці товари мають різну вартість і своє коло користувачів.

3 іншого боку, темпоральне пояснення визначає об'єктивну потребу споживачів у рекомендованому товарі або послузі, а також зміну цієї потреби 3 часом.

\section{Висновки}

Запропоновано інформаційну технологію побудови деталізованих пояснень щодо рекомендацій 3 урахуванням змін потреб користувачів з часом.
Технологія використовує адаптовані моделі темпоральних правил, а також модель інтерфейсу пояснень 3 темпоральними параметрами.

Адаптовані темпоральні правила мають вагу, яка обчислюється на основі різниці продажів на визначених інтервалах в рамках заданого періоду часу, що дає можливість врахувати зміни інтересів споживачів з часом.

Модель інтерфейсу пояснень відображає темпоральну динаміку вподобань користувачів на основі комбінації кількісних та якісних показників змін продажів предметів з можливістю ітеративного визначення періоду часу для обчислення цих показників.

Технологія містить фази побудови пояснень 3 урахуванням темпоральної динаміки вподобань користувачів, деталізації пояснень на основі узгодження темпоральних знань, а також уточнення даних для інтерфейсу пояснень 3 відображенням темпоральних змін у виборі споживачів.

Принципова відмінність розробленої технології від існуючих підходів до побудови пояснень полягає у врахуванні циклічних коливань уподобань користувачів, а також еволюційних змін у вимогах споживачів в результаті впливу зовнішніх факторів (сезонні зміни, переміна місця роботи, освіти, тощо).

Обмеження технології пов'язані із вимогами відображення часу у вхідних даних або упорядкування таких даних у часовому вимірі, що $\epsilon$ необхідною умовою для побудови темпоральних правил.

У практичному аспекті технологія забезпечує можливості для підвищення довіри споживача до отриманого рекомендованого переліку товарів та послуг, оскільки дає можливість відобразити динаміку попиту на рекомендовані товари.

Тим самим, використання технології забезпечує для користувача раціональне підтвердження рекомендації i, як наслідок, сприяє збільшенню продажів в системі електронної комерції.

\section{REFERENCES}

1. Izquierdo-Castillo, J. (2015). The new media business concept led by Netflix: A study of the model and its projection into the Spanish market. El Profesional de la Informacion, 24 (6), 819-826. 24. 819. doi: 10.3145/epi.2015.nov.14. Available at: https://recyt.fecyt.es/index.php/EPI/article/view/epi.2015.nov.14.

2. Fararni K., Aghoutane B., Riffi J., Abdelouahed S. (2020). Comparative Study on Approaches of Recommendation Systems. Embedded Systems and Artificial Intelligence, 753-764. doi: 10.23919/AEIT.2018.8577311. Available at: https://www.researchgate.net/publication/340497029_Comparative_Study_on_Approaches_of_Recommendation_System

3. Chalyi, S., Leshchynskyi, V., Leshchynska, I. (2019). Method of forming recommendations using temporal constraints in a situation of cyclic cold start of the recommender system. EUREKA: Physics and Engineering, 4, 34-40. doi: https://doi.org/10.21303/2461-4262.2019.00952 . Available at: http://eu-jr.eu/engineering/article/view/952/934.

4. Chala, O., Novikova, L., Chernyshova, L. (2019). Method for detecting shilling attacks in e-commerce systems using weighted temporal rules. EUREKA: Physics and Engineering, 5, 29-36. doi: 10.21303/2461-4262.2019.00983 http://eujr.eu/engineering/article/view/983/966. Available at: http://eu-jr.eu/engineering/article/view/983/966.

5. Lops P., Jannach D., Musto C., Bogers T., Koolen M. (2019). Trends in content-based recommendation. User Modeling and User-Adapted Interaction, 29, 239-249. doi: https://doi.org/10.1007/s11257-019-09231-w. Available at: https://link.springer.com/article/10.1007/s11257-019-09231-w.

6. Tsai C., Brusilovsky P. (2019). Explaining recommendations in an interactive hybrid social recommender. Proceedings of the 24th International Conference on Intelligent User Interfaces (IUI '19), 391-396. doi: 10.1145/3301275.3302318. Available at: https://dl.acm.org/doi/abs/10.1145/3301275.3302318.

7. Dominguez V., Messina P., Donoso-Guzmán I., Parra D. (2019). The effect of explanations and algorithmic accuracy on visual recommender systems of artistic images. Proceedings of the 24th International Conference on Intelligent User In- 
terfaces (IUI '19), 408-416. doi: https://doi.org/10.1145/3301275.3302274. Available at: https://dl.acm.org/doi/abs/10.1145/3301275.3302274.

8. Rana, K. Jain, C.S. (2015). A study of the dynamic features of recommender systems. Artificial Intelligence Review, 43(1), 141-153. doi: https://doi.org/10.1007/s10462-012-9359-6. Available at: https://link.springer.com/article/10.1007/s10462-012-9359-6.

9. Zhou X., Sun Z., Guo G., Liu Y. (2020). Modelling Temporal Dynamics and Repeated Behaviors for Recommendation. 24th Pacific-Asia Conference Advances in Knowledge Discovery and Data Mining (PAKDD 2020), 12084, 181-193. doi: 10.1007/978-3-030-47426-3 15. Available at: https://link.springer.com/content/pdf/10.1007\%2F978-3-030-47426-3_15.pdf

10. Liu D., Chen K., Chou Y., Lee J. (2018). Online Recommendations based on Dynamic Adjustment of Recommendation Lists. Knowledge-Based Systems, 161, 375-389. doi: 10.1016/j.knosys.2018.07.038. Available at: https://www.sciencedirect.com/science/article/abs/pii/S0950705118303915.

11. Cunningham, P., Doyle, D., Loughrey, J. (2003) An Evaluation of the Usefulness of Case-Based Reasoning Explanation. In: Case-Based Reasoning Research and Development:Proceedings ICCBR. Number 2689 in LNAI, Trondheim, Springer, pp. $122-130$.

12. Cleger S., Fernndez-Luna J., F Huete J. (2014). Learning from explanations in recommender systems. Information Sciences. Information Sciences, 287, pp.90-108. .

13. Chalyi S., Leshchynskyi V., Leshchynska I. (2019). Моделювання пояснень щодо рекомендованого переліку об’єктів з урахуванням темпорального аспекту вибору користувача. Системи управління, навігації та зв'язку, 6 (58), 97-101. - doi:https://doi.org/10.26906/SUNZ.2019.6.097.

14. Chalyi, S., Leshchynskyi, V. (2020). Method of constructing explanations for recommender systems based on the temporal dynamics of user preferences. EUREKA: Physics and Engineering, 3, 43-50. doi: 10.21303/2461-4262.2020.001228. Available at: http://journal.eu-jr.eu/engineering/article/view/14.

15. Levykin V., Chala O. (2018). Development of a method for the probabilistic inference of sequences of a business process activities to support the business process management. Eastern-European Journal of Eenterprise Technologies, 5/3(95), 16-24. DOI: $10.15587 / 1729-4061.2018 .142664$.

16. Chalyi S., Leshchynskyi V., Leshchynska I. (2020). Detailing explanations in the recommender system based on matching temporal knowledge. Eastern-European Journal of Eenterprise Technologies, 4/2 (106), 6-13. DOI: 10.15587/17294061.2020.210013

17. Чалий С.Ф., Лещинський В.О., Лещинська I.О. (2020). Модель інтерфейсу пояснень 3 темпоральними параметрами в рекомендаційній системі. Системи управління, навігації та зв'язку, 2(60), 105-109. DOI: https://doi.org/10.26906/SUNZ.2020.2.105

18. Чалий С.Ф., Лещинський В.О., Лещинська І.О. (2018). Моделювання контексту в рекомендаційних системах. Проблеми інформаційних технологій, 1(023), 21-26.

Received (Надійшла) 22.07.2020

Accepted for publication (Прийнята до друку) 02.09.2020

\section{Information technology of construction of explanations considering temporal changes in requirements of the recommender system's users}

S. Chalyi, V. Leshchynskyi, I. Leshchynska

Abstract. The subject matter of the article is the processes of forming explanations for personalized recommendations for the choice of goods and services in recommendation systems. The goal is to develop an information technology for constructing detailed explanations regarding the proposed personal list of items in a recommendation system, taking into account temporal changes in consumer requirements to improve the efficiency of sales of goods and services in e-commerce systems. Tasks: development of an approach to the construction of temporal rules for the formation of an explanation based on the comparison of the number of sales on a sequence of time intervals; development of technology for constructing temporally oriented explanations regarding recommendations for choosing subjects in e-commerce systems. The approaches used are: approaches to constructing explanations regarding recommendations, taking into account changes in user preferences over time. The following results were obtained. An approach to the construction of temporal rules that determine the temporal dynamics of the preferences of the users of the recommender system has been developed. Using temporal rules, a technology for constructing and detailing explanations has been developed, taking into account changes in user requirements over time. Conclusions. The scientific novelty of the results obtained is as follows. An information technology is proposed for constructing detailed explanations regarding recommendations taking into account changes in user requirements over time. The technology uses temporal rule models and a temporal explanation interface model. The technology provides for the sequential construction of basic explanations taking into account the temporal dynamics of user preferences, further detailing of explanations by time intervals based on the coordination of temporal knowledge, as well as the formation of an interface of detailed explanations with the display of basic changes in user preferences and alternative changes at separate time intervals. In practical terms, the technology is focused on increasing consumer confidence in the received recommendation based on the reflection of changes in demand for the recommended products. The use of technology ensures the formation of a rational confirmation of the recommendation for the user in the form of a combination of quantitative and qualitative indicators, contributes to an increase in sales in the corresponding e-commerce system.

Keywords: recommender systems, explanation, formation of recommendations, formation of explanations, criteria for evaluating explanations, temporal rules. 